\section{Miscellaneous rheumatic diseases}

\section{AB0207 REFLEX SYMPATHETIC DYSTROPHY ASSOCIATED WITH PHENOBARBITAL}

JA Hernandez-Beriain, A Rosas, E Girona. Rheumatology Section, Hospital Insular, Las Palmas de GC, Spain

10.1136/annrheumdis-2001.728

Background Reflex sympathetic dystrophy (RSD) is a complex syndrome characterised by pain and oedema of one or more extremities, trophic skin changes and vasomotor instability. Long-term outcome is variable and can induce severe consequences. Barbiturates has been related with RSD in $15 \%$ of the cases. Objectives The aim of our work is to define long-term outcome and response to therapy of three patients with RSD following barbiturates use.

Methods

Results Main results are expressed in the next Table 1:

\begin{tabular}{|c|c|c|c|c|c|}
\hline & $\begin{array}{l}\text { Sex } \\
\text { and } \\
\text { age }\end{array}$ & Distribution & $\begin{array}{l}\text { Response to } \\
\text { barbiturates } \\
\text { discontinuation }\end{array}$ & $\begin{array}{l}\text { Response to } \\
\text { steroids/ } \\
\text { calcitonin }\end{array}$ & $\begin{array}{l}\text { Sequels } \\
\text { (1 year) }\end{array}$ \\
\hline $\begin{array}{l}\text { Patient } \\
1\end{array}$ & $\begin{array}{l}\text { Male/ } \\
70\end{array}$ & $\begin{array}{l}\text { Both upper } \\
\text { limbs }\end{array}$ & No & No & + \\
\hline $\begin{array}{l}\text { Patient } \\
2\end{array}$ & $\begin{array}{l}\text { Female/ } \\
60\end{array}$ & $\begin{array}{l}\text { Both upper } \\
\text { limbs }\end{array}$ & No & No & + \\
\hline $\begin{array}{l}\text { Patient } \\
3\end{array}$ & $\begin{array}{l}\text { Female/ } \\
54\end{array}$ & $\begin{array}{l}\text { Right upper } \\
\text { limb }\end{array}$ & \pm & + & \pm \\
\hline
\end{tabular}

Conclusion RSD can be induced with barbiturates therapy. In our experience barbiturates discontinuation is insufficient for improving and response to other therapies can be limited with significant long-term disability.

\section{AB0208 CYCLOPHOSPHAMIDE MAY INDUCE REMISSION OF RELAPSING POLYCHONDRITIS REFRACTORY TO CORTICOSTEROIDS}

${ }^{1} \mathrm{~N}$ Kyriazis, ${ }^{2} \mathrm{~J}$ Dais, ${ }^{2} \mathrm{E}$ Archontis, ${ }^{2} \mathrm{H}$ Exarhou, ${ }^{2} \mathrm{~A}$ Koumaditis. ${ }^{1}$ Rheumatology Department; ${ }^{2}$ Second Department of Internal Medicine, General Prefectural Hospital of Karditsa, Karditsa, Greece

\subsection{6/annrheumdis-2001.729}

Background Relapsing polychondritis (RP) is so rare that controlled therapy trials have not been carried out. Therefore, strategies for the treatment of RP refractory to moderate- or highdose corticosteroids (CS) have not been established.

Objectives To report a severe case of RP, refractory to CS, in which complete remission was induced by cyclophosphamide (CP) therapy.

Methods Retrospective clinical and laboratory analysis of one patient.

Results A 55-year-old Caucasian woman developed ear and nose cartilage inflammation, for the first time, when she was 31. At that time a biopsy of auricular cartilage confirmed the clinical diagnosis of RP. The disease responded to an initial short-term CS therapy (20 mg prednisolone/day), but a maintenance dose of 5-10 mg prednisolone/day was required to control symptoms and prevent relapses ever since. Meanwhile, she developed diabetes mellitus and cataract. Additionally, she had chronic anaemia due to thalassemia minor. Sixteen months ago, after strenuous physical exercise, a severe relapse of the disease occurred suddenly. The patient presented with acute arthritis of the knees and wrists, chondritis of the auricular, nasal, and laryngotracheal cartilages, as well as symptoms of eye inflammation. She complained of severe arthralgias, hoarseness, cough, eye irritation, tinitus, and vertigo. Physical examination revealed fever $\left(38^{\circ} \mathrm{C}\right)$, tenderness of thyroid cartilage and the anterior trachea, bilateral episcleritis and cataract, cochlear and vestibular dysfunction, and effusion of both knees. Laboratory investigation showed an erythrocyte sedimentation rate of $41 \mathrm{~mm}$, C-reactive protein $15.5 \mathrm{mg} / \mathrm{dl}$ (normal <0.9 $\mathrm{mg} / \mathrm{dl}$ ), glucose $216 \mathrm{mg} / \mathrm{dl}$, hematocrit 35\%, haemoglobin concentration $10.3 \mathrm{~g} / \mathrm{dl}$, white blood cell count $10,540 / \mu \mathrm{l}$ with $71 \%$ polymorphs, platelet count $477,000 / \mu \mathrm{l}$, negative rheumatoid factor, microscopic hematuria, and inflammatory synovial fluid, containing 15,800 white cells $/ \mu$ 1 (95\% polymorphs, 5\% lymphocytes), but no crystals or microorganisms. The manifestations of laryngotracheal, ocular, and inner ear inflammation were refractory to $60 \mathrm{mg}$ prednisolone/ day for four weeks. Then, oral CP $(1.5 \mathrm{mg} / \mathrm{Kg} / \mathrm{day})$ was added and a quick improvement ensued. Within four months of CP therapy complete clinical remission of the disease and normalisation of laboratory tests was observed. Subsequently, CP was discontinued and prednisolone was gradually tapered off over the next six months. Eventually, five months after stopping CS, the disease still remains quiescent without therapy.

Conclusion Although RP may have a remitting course, the remission in our patient has most likely been induced by CP in combination with prednisolone. Our observation suggests that $\mathrm{CP}$ is an effective therapy for severe cases of RP refractory to CS alone. Moreover, CP seems capable of inducing sustained remission of this disease.

\section{AB0209 LONG TERM ANALYSIS AND EVALUATION OF SIDE EFFECTS RELATED TO CYCLOSPORINE TREATMENT OF 59 PATIENTS WITH RHEUMATIC DISEASES}

MM Martinez-Losa, HC Macias, EM Camargo, AR De la Serna, CD López, JM Llobet, CG Ferrer. Rheumatology, Hospital de La Santa Creu I Sant Pau, Barcelona, Spain

\subsection{6/annrheumdis-2001.730}

Background Cyclosporine has been used in the area of rheumatology, and various published articles describe evidence of side effects in short and long term, which have lead to withdrawal of the treatment.

Objectives Evaluate the presence of side effects in 59 patients that received cyclosporine treatment in dosis of $2.5-3 \mathrm{mg} / \mathrm{Kg}$ / day.

Methods This is a prospective study which carried out 59 patients that received cyclosporine treatment: 45 females with an average age of 57 years (range 23-80) and 15 males with an average age of 50.6 years (range $31-72$ ) with the follow disease: 41 Rheumatoid Arthritis, 6 Psoriatic Arthritis and tha remainder included sufferers of Systemic Lupus Erythematosus, Scleroderma, Ankylosing Spondylitis and Cryoglobulinemia. Female patients suffering from the illness for an average of 19.95 years, were treated for a total period of 22.11 months. Male patients suffering from the illness for an average of 8.7 years, were treated for a total period of 19.4 months. 
Results Reasosn for treatment withdrawal were: a) increase in levels of creatinine in 27 out of 59 patients causing treatment suspension for 3 patients; b) nausea and vomiting in 8 cases; c) 6 out of 8 patients presenteds hypertension; d) 11 patients suffered from headache and treatment was withdrawn in 4 cases; e) 13 patients showed increase of levels of alkaline phosphatse, 3 of them were under combined methotrexate treatment; $f$ ) other causes: diarrhoea (4), dermatitis (1), trombocytopenia (1) and metrorrhagias (1).

Conclusion Cyclosporine is an effective treatment for the rheumatic diseases, neverthless, the side effects have forced us to withdraw treatment for half of patients under the study.

\section{REFERENCE}

1 Lynch AR. 2000;43:5344

\section{AB0210 STUDYING OF THEW EFFICIENCY OF THE SYNVISK IN OSTEOPARTHROSIS}

LD Groppa, M Moschneaga. Rheumatology, Chisinau State University of Medicine and Pharmaceutics, Republic of Moldova., Chisinau, Republic of Moldova

\subsection{6/annrheumdis-2001.731}

Background At present for improvement of life quality in patients with osteoarthrosis is necessary to solve some problems: precluding of development of degenerative process in cartilage of affected joint, relieving of pain and improving of the function of the joint.

Objectives

Methods For these aims we studied the efficiency of the chondroprotective drug Synvisk by Boehringer Ingelheim in 25 patients with arthrosis of the knee in medium age of $61.2 \pm 1.7$ years, 16 women and 8 men, with duration of the disease $5.8 \pm$ 0.9 years. Conform X-ray data the distribution of the patients by stages of the disease was as follow: I grade ? 20\%, II grade ? $64 \%$, and III grade ? $16 \%$. In experimental group the drug was administered intraarticular by blind method in dose of $2.0 \mathrm{ml}$ one time in a week, 3 injections for the course, which were repeated after 6 and 12 months. The control group was matched by gender, duration of disease and X-ray date; in this group was administrated placebo conform same scheme. Evaluation of the effectiveness and tolerability of compared drugs was carried out in evolution of clinical (pain, functional index by Lesquesne, volume of movement on affected joints), X-ray parameters and functional methods (ultrasonography, scintigraphy with Te99m. Results In the basic group were mentioned decreasing of the pain intensity and improvement of the joint functions just after single injection in one third of the patients, while in control groups similar cases were absent. After 3 courses of the treatment in the basic group the effects were obtained in $86.7 \%$ of the patients, including $33.3 \%$ very good effect, in $53.4 \%$ moderate effect and only in $13.3 \%$ the effects were absent. In control group there were no effects in $80 \%$ of the patients, and in $20 \%$ of the patients there were mentioned moderate effects; good effects were are not observed.

Conclusion Thus, presented results suggests that administration of Synvisk lead to significant improvement of the life quality in the patients with arthrosis of the knee.

\section{AB0211 STUDYING OF THE EFFICIENCY OF THE SYNVISK IN OSTEOPARTHROSIS}

LD Groppa, M Moschneaga. Rheumatology, Chisinau State University of Medicine and Pharmaceutics, Republic of Moldova., Chisinau, Republic of Moldova

10.1136/annrheumdis-2001.732

Background At present for improvement of life quality in patients with osteoarthrosis is necessary to solve some problems: precluding of development of degenerative process in cartilage of affected joint, relieving of pain and improving of the function of the joint.

Objectives

Methods For these aims we studied the efficiency of the chondroprotective drug Synvisk by Boehringer Ingelheim in 25 patients with arthrosis of the knee in medium age of $61.2 \pm 1.7$ years, 16 women and 8 men, with duration of the disease $5.8 \pm$ 0.9 years. Conform X-ray data the distribution of the patients by stages of the disease was as follow: I grade ? 20\%, II grade ? $64 \%$, and III grade ? $16 \%$. In experimental group the drug was administered intraarticular by blind method in dose of $2.0 \mathrm{ml}$ one time in a week, 3 injections for the course, which were repeated after 6 and 12 months. The control group was matched by gender, duration of disease and X-ray date; in this group was administrated placebo conform same scheme.

Evaluation of the effectiveness and tolerability of compared drugs was carried out in evolution of clinical (pain, functional index by Lesquesne, volume of movement on affected joints), Xray parameters and functional methods (ultrasonography, scintigraphy with $\mathrm{Te} 99 \mathrm{~m}$.

Results In the basic group were mentioned decreasing of the pain intensity and improvement of the joint functions just after single injection in one third of the patients, while in control groups similar cases were absent. After 3 courses of the treatment in the basic group the effects were obtained in $86.7 \%$ of the patients, including $33.3 \%$ very good effect, in $53.4 \%$ moderate effect and only in $13.3 \%$ the effects were absent. In control group there were no effects in $80 \%$ of the patients, and in $20 \%$ of the patients there were mentioned moderate effects; good effects were are not observed.

Conclusion Thus, presented results suggests that administration of Synvisk lead to significant improvement of the life quality in the patients with arthrosis of the knee.

\section{AB0212 EXPERIENCE WITH INTRAVENOUS IMMUNOGLOBULIN THERAPY IN TWENTY PATIENTS WITH DIFFERENT AUTOIMMUNE RHEUMATIC DISEASES}

S Kamali, A Gül, M Inanç, A Çefle, M Sayarlioglu, O Aral, M Koniçe. Internal Medicine, Division of Rheumatology Department of Internal Medicine Istanbul Faculty of Medicine University of Istanbul, Istanbul, Turkey

\subsection{6/annrheumdis-2001.733}

\section{Background}

Objectives Retrospective evaluation of high dose intravenous immunoglobulin (IVIG) treatment in patients with connective tissue diseases.

Methods We evaluated the records of 8 patients with systemic lupus erythematosus (SLE), 8 patients with inflammatory muscle disease [polimyositis (PM), juvenil dermatomyositis (JDM), dermatomyositis (DM)] and 4 patients with Wegener's granulomatosis (WG) who received $2 \mathrm{~g} / \mathrm{kg}$ IVIG in 5 days 1-12 times monthly. 